\title{
Aortic injuries in crush trauma patients: different mechanism, different management
}

\author{
Victor X. Mosquera, Milagros Marini, Javier Muñiz, José M. López-Pérez, Daniel \\ Gulías, José J. Cuenca
}

\begin{abstract}
Background. The objective of this study is to report the clinical and radiological characteristics and early and longterm survival of a series of acute traumatic aortic injuries (ATAI) in crush trauma patients, and to compare such data with our last 30 years experience managing ATAI in deceleration non-crush trauma patients.

Methods. From January 1980 to December 2010, 5 consecutive ATAI in crush trauma and 69 in non-crush trauma patients were admitted at our institution. ISS, RTS and TRISS scores were similar in both groups.

Results. Overall in-hospital mortality was $24.3 \%$. There was no in-hospital mortality in crush patients and $26.1 \%$ in non-crush patients $(p=0.32)$.

All aortic-related complications occurred in non-crush patients. Median follow-up was 129 months (range 3-350 months). Non-crush group survival was $76.8 \%$ at 1 year, $73.6 \%$ at 5 years, and $71.2 \% \%$ at 10 years. There was no mortality during follow-up in the crush group. Mean (SD) peak creatine phosphokinase was significantly higher in crush group than in non-crush group: 7598 (3690) IU/L vs. 3645 (2506) IU/L; $p=0.041$. Incidence of acute renal injury was higher in crush trauma patients $(100 \%$ vs. $36.2 \% ; p=0.018)$. Low-severity injuries were more common in crush trauma patients ( $100 \%$ in crush patients vs. $43.5 \%$ in non-crush patients, $p=0.04$ ).

Conclusions. Aortic injuries in crush thoracic trauma patients seem to present in a different clinical scenario from aortic injuries in high-speed thoracic trauma thus requiring distinct considerations. When planning the initial management of aortic injuries in crush trauma, the increased risk of rhabdomiolysis and subsequent acute renal failure, as well as a tendency to develop lower-risk aortic wall injuries, must be considered.
\end{abstract}

\section{Keywords}

Emergency medicine; Aorta; Endovascular; Surgery

Blunt rupture of the thoracic aorta may occur in patients with multisystem trauma and has devastating consequences. ${ }^{1}$ The most common mechanism of acute traumatic aortic injury (ATAI) is the shearing stress to the aorta during rapid deceleration and appears in motor vehicle injuries and falls. ${ }^{2}$ However, there are other mechanisms such as compression of the aorta between sternum and thoracic spine (osseous pinch), and direct load causing aortic wall strain and medial tears. ${ }^{2,3}$ and 4 The latter would explain how the aorta is injured in thoracic trauma due to crush.

Clinical and radiological characteristics and both in-hospital and long-term survival of ATAI in crush trauma is poorly documented. All the studies published to date are only focused on aortic injuries in deceleration non-crush trauma patients, there being a lack of information about ATAI in crush trauma patients. In fact, the different mechanism of ATAI and the special clinical features of patients with ATAI and crush syndrome may require a management distinct from the one in deceleration trauma ATAI.

The objective of this study is to report the clinical and radiological characteristics and early and longterm survival of a series of 5 consecutive ATAI in crush trauma patients, and to compare such data with our last 30 years experience managing ATAI in trauma patients. 


\section{Patients and methods}

From January 1980 to December 2010, 80 patients were admitted to our institution with ATAI. Six patients were excluded from the analysis because of deficient documentation of the time from injury to procedure and/or in extremis status on arrival. Five patients suffered ATAI in a crush trauma, whilst the remaining 69 patients presented a more common deceleration non-crush trauma. Flow diagram in Fig. 1 depicts the flow of patients.

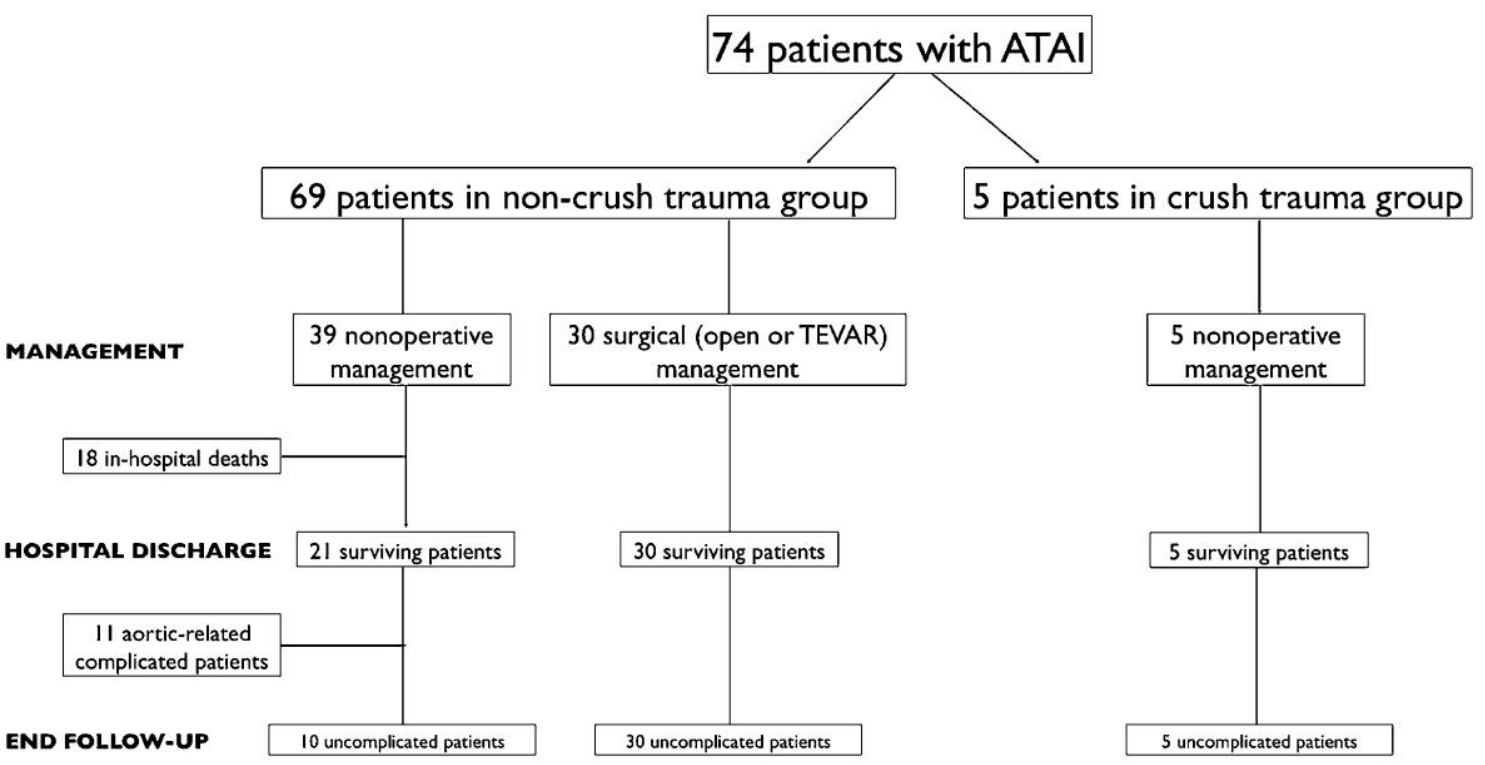

Fig. 1. Flow chart depicts the patient distribution at 3 different stages (management; hospital discharge; follow-up). ATAI: acute traumatic aortic injury. TEVAR: thoracic endovascular aortic repair.

Data collection included age, gender, mechanism of injury, initial clinical presentation (blood pressure, Glasgow coma scale [GCS]), injury severity score (ISS), ${ }^{5}$ abbreviated injury score (AIS) for each body area (head, chest, abdomen, and extremities), revised trauma score (RTS), ${ }^{6}$ trauma injury severity score (TRISS), ${ }^{7}$ method of diagnosis (computed tomography scan, angiography, and transesophageal echocardiogram), and peak serum creatine phosphokinase (CPK).

Aortic injuries were classified according to the classification proposed by Azizzadeh et al. in 2009 in type I (intimal tear), type II (intramural haematoma), type III (pseudoaneurysm), or type IV (rupture). ${ }^{8 \text { and }} 9$ Types I and II were considered low-risk injuries, and types III and IV high-risk injuries.

Aortic injuries were also classified according to the site of aortic injury (aortic root-ascending aorta; aortic arch; aortic isthmus; mid and/or distal descending thoracic aorta), and the type of definitive management (conservative, open repair or endovascular repair).

An ISS score of more than 50 points predicts a mortality rate of over $50 \%$, whilst a score of more than 70 points predicts a mortality rate of nearly $100 \% .^{5}$ The TRISS score directly predicts the expected death rate for blunt trauma. ${ }^{7}$

Acute renal injury (ARI) was defined using published criteria as changes in serum creatinine (increase in serum creatinine by twofold or decrease in glomerular filtration rate $>50 \%$ ) or changes in urine output (urine output $<0.5 \mathrm{ml} / \mathrm{kg} / \mathrm{h}$ during $12 \mathrm{~h}$ ), or both. ${ }^{10}$ Acute renal failure (ARF) was defined using published criteria as changes in serum creatinine (increase in serum creatinine by threefold; serum creatinine $\geq 4.0 \mathrm{mg} / \mathrm{dl}(350 \mu \mathrm{mol} / \mathrm{l})$ with an acute increase of at least $0.5 \mathrm{mg} / \mathrm{dl}(44 \mu \mathrm{mol} / \mathrm{l})$, or a decrease in glomerular filtration rate $>75 \%$ ) or changes in urine output (urine output $<0.3 \mathrm{ml} / \mathrm{kg} / \mathrm{h}$ during $24 \mathrm{~h}$ or anuria during $12 \mathrm{~h}$ ), or both. ${ }^{10}$

Patient management was conservative treatment, aortic endografting or open surgical repair according to the clinical and radiological criterion of the trauma team involved. The criteria of patient management were modified with the incorporation of technological advances in both diagnostic and therapeutic fields, especially with the spread of thoracic aorta endografting. ${ }^{11}$

Institutional Review Board approval was obtained. 


\section{Statistical analysis}

Data are expressed as mean and standard deviation or median and range, when appropriate. Proportions were compared with contingency tables by means of Chi-square with Yates' correction or Fisher's exact tests when appropriate, whilst the Student's $t$-test or Wilcoxon rank sum test were used to continuous variables. A $p$ value of less than 0.05 was considered significant.

Actuarial estimates of survival were accomplished with Kaplan-Meier methods. Differences in probability of survival between the groups were analysed with the Log Rank (Mantel-Cox) test.

The SPSS statistical program (except 'program' in computers) for Windows version 17.0 (SPSS, Chicago, IL) was used to perform data analysis.

\section{Results}

Epidemiologic and clinical characteristics of the 5 crush trauma patients are described in Table 1. Fig. 2 shows imaging tests in crush trauma patients confirming the presence of ATAI. During the study period, 69 non-crush trauma patients with ATAI were also admitted to our institution. Differences in epidemiologic and clinical characteristics between crush trauma and non-crush trauma patients are shown in Table 2.

Overall expected mortality at admission was $\geq 50 \%$ according to an ISS score $>50$ points in $22.9 \%$ of patients, whilst overall mean (SD) expected death rate calculated by TRISS score was $34.96 \%$ (35.76\%).

All thoracic or thoracoabdominal crush trauma were the result of occupational accidents and were caused by compression by heavy machinery, blocks of stones, trunks, etc. In the non-crush group, the cause of the trauma was a car accident in 44 cases, a motorbike accident in 11, falls in 8 and a pedestrianvehicle accident in 6 cases.

There were no statistically significant differences in the overall presence of severe extrathoracic injuries and expected mortality calculated by ISS, RTS and TRISS scores (Table 2). However, no patient in the crush group presented severe head and neck injury (head \& neck AIS > 3) vs. 10 patients $(14.5 \%)$ in the non-crush group.

Mean (SD) peak CPK was significantly higher in the crush group than in the non-crush group (7598 (3690) IU/L vs. 3645 (2506) IU/L; $p=0.041)$. All patients in the crush group had a peak CPK > $2000 \mathrm{IU} / \mathrm{L}$, whilst 49 patients $(71 \%)$ in the non-crush group presented a peak CPK > $2000 \mathrm{IU} / \mathrm{L}$ $(p=0.31)$

ARI occurred in 5 crush trauma patients $(80 \%)$ and in 25 non-crush trauma patients $(36.2 \%)$ $(p=0.018)$. Only one case in the crush trauma group presented ARF and required haemodiafiltration.

In the crush trauma group, aortic injuries occurred at the aortic arch ( 2 cases, $40 \%)$, mid and distal descending aorta ( 2 cases, 40\%) and aortic isthmus (1 case, 20\%). However, in the non-crush trauma group most of aortic injuries were located at isthmus level (45 cases, 65.2\%) followed in frequency by the mid and distal thoracic descending aorta (14 cases, $20.3 \%)$, aortic arch ( 5 cases, $7.2 \%)$, ascending aorta (3 cases, $4.3 \%$ ), and abdominal aorta ( 2 cases, $2.9 \%$ ). Table 3 shows the differences in the types of aortic injury. Crush trauma patients only presented low-severity injuries (types I-II) (5 patients, 100\%), the proportion of low-severity injuries in the non-crush group being significantly smaller (30 patients, $43.5 \%$ ) $(p=0.04)$ 
Table 1. Epidemiologic and clinical characteristics in crush trauma patients.

\begin{tabular}{|c|c|c|c|c|c|c|c|c|c|c|c|c|c|}
\hline $\begin{array}{l}\text { Crush } \\
\text { patient } \\
(n=5)\end{array}$ & Sex & $\begin{array}{l}\text { Age } \\
\text { (years) }\end{array}$ & $\begin{array}{l}\text { Mechanism of } \\
\text { trauma }\end{array}$ & Site of injury & Type of injury & GCS & Hypotension & $\begin{array}{l}\text { Head } \\
\text { AIS }\end{array}$ & Abdomen AIS & Extremity AIS & $\begin{array}{l}\text { Peak CPK } \\
\text { (IU/L) }\end{array}$ & ARI & $\mathrm{HDF}$ \\
\hline 1 & M & 34 & $\begin{array}{l}\text { Crushed under a } \\
\text { caterpillar tractor }\end{array}$ & Aortic isthmus & $\begin{array}{l}\text { Partial intimal } \\
\text { tear }\end{array}$ & 7 & Yes & 3 & 2 & 5 & 19,272 & Yes & Yes \\
\hline 2 & M & 45 & $\begin{array}{l}\text { Crushed under a } \\
\text { tractor }\end{array}$ & Aortic arch & $\begin{array}{l}\text { Partial intimal } \\
\text { tear }\end{array}$ & 13 & Yes & 3 & 1 & 3 & 5142 & Yes & No \\
\hline 3 & M & 66 & $\begin{array}{l}\text { Crushed under a } \\
\text { tractor }\end{array}$ & Aortic arch & $\begin{array}{l}\text { Intramural } \\
\text { haematoma }\end{array}$ & 15 & No & 1 & 4 & 4 & 2300 & Yes & No \\
\hline 4 & M & 40 & $\begin{array}{l}\text { Crushed under a } \\
\text { concrete block }\end{array}$ & $\begin{array}{l}\text { Mid-descending } \\
\text { aorta }\end{array}$ & $\begin{array}{l}\text { Partial intimal } \\
\text { tear }\end{array}$ & 15 & Yes & 4 & 2 & 3 & 9113 & Yes & No \\
\hline 5 & M & 40 & $\begin{array}{l}\text { Crushed under a } \\
\text { trunk }\end{array}$ & $\begin{array}{l}\text { Mid-descending } \\
\text { aorta }\end{array}$ & $\begin{array}{l}\text { Partial intimal } \\
\text { tear }\end{array}$ & 15 & No & 1 & 5 & 2 & 2165 & No & No \\
\hline
\end{tabular}

$\mathrm{M}=$ male; $\mathrm{GCS}$ = Glasgow coma scale; AIS = abbreviated injury score; $\mathrm{CPK}$ = creatine phosphokinase; $\mathrm{ARI}$ = acute renal injury; HDF = haemodiafiltration 


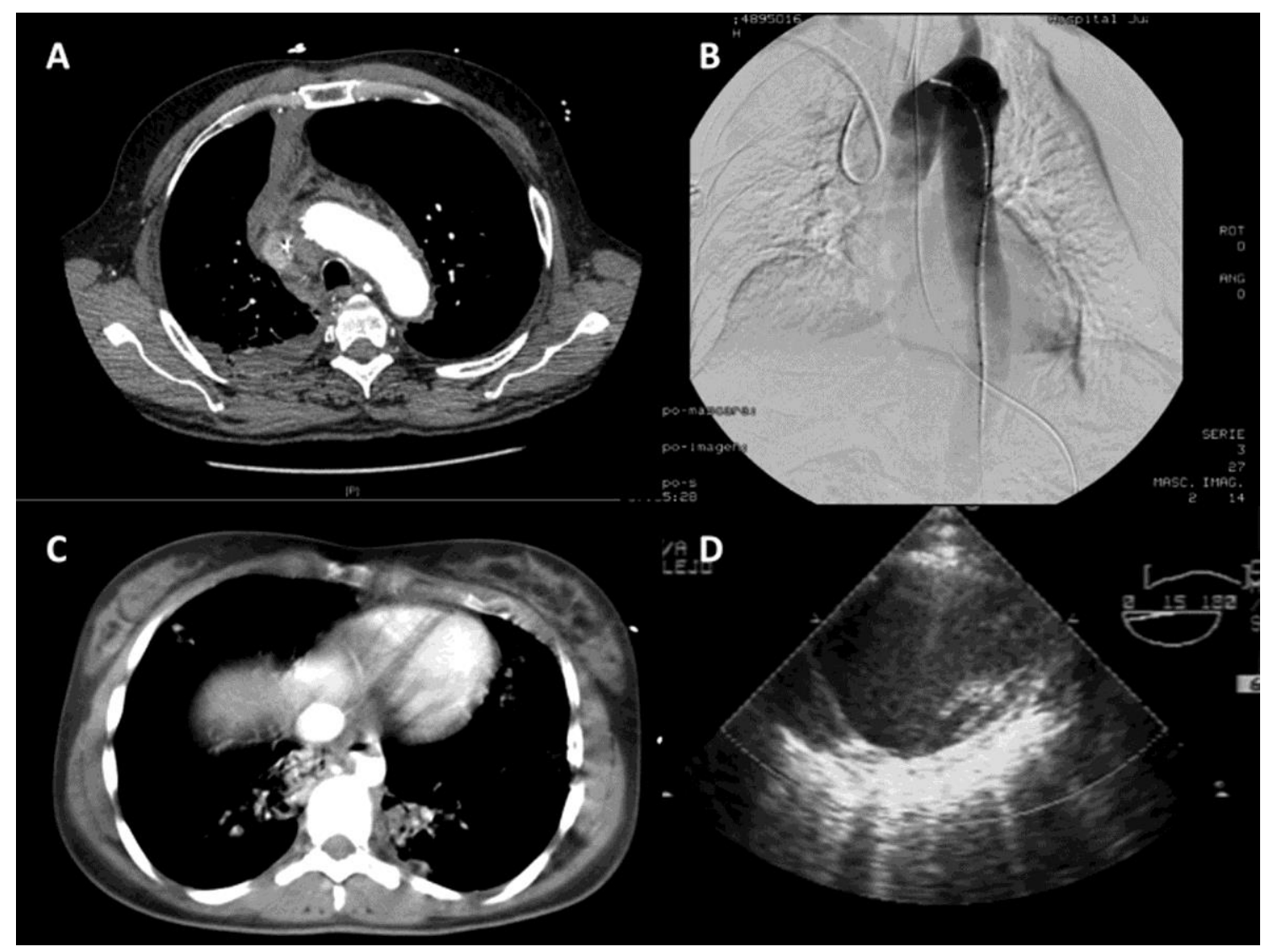

Fig. 2. (A) CT scan axial slide showing an aortic arch type II injury in a 66-year-old male crushed under a tract. (B). Aortography showing a small type I injury in a 34-year-old male crushed under a caterpillar tractor. (C) CT scan axial slide showing a middescending aorta type I injury in a 40-year-old male crushed under a concrete block. The transesophageal echocardiogram (D) confirmed a small type I injury.

Table 2. Epidemiologic and clinical characteristics in all patients, crush and non-crush trauma groups.

\begin{tabular}{lllll}
\hline & All patients $(n=74)$ & Crush trauma group $(n=5)$ & Non-crush trauma group $(n=69)$ & $p$ Value \\
\hline Male & $62(83.8 \%)$ & $5(100 \%)$ & $57(82.6 \%)$ & 0.58 \\
Age (years) & $40.9(18.1)$ & $45.01(12.36)$ & $40.16(18.01)$ & 0.081 \\
Mean (SD) & $19(25.7 \%)$ & $1(20 \%)$ & $18(26.1 \%)$ & 0.61 \\
Age >55 years & $38.96(13.89)$ & $36.4(9.23)$ & $39.15(14.22)$ & 0.67 \\
ISS mean (SD) & $6.17(0.67)$ & $6.08(1.74)$ & 0.91 \\
RTS mean (SD) & $6.09(1.68)$ & $29.9(23.14)$ & $35.34(36.62)$ & 0.74 \\
TRISS mean (SD) & $34.96(35.76 \%)$ & 0 & $10(14.5 \%)$ & 0.81 \\
Head AIS > 3 & $10(13.5 \%)$ & $2(40 \%)$ & $27(39.3 \%)$ & 0.29 \\
Abdomen AIS > 3 & $16(21.6 \%)$ & $2(40 \%)$ & & 0.96 \\
Extremity AIS > 3 & $29(39.2 \%)$ & & & \\
\hline
\end{tabular}

The $p$ value of proportions analysis was obtained with the $\chi^{2}$ with Yates' correction or Fisher's exact test, whilst $p$ values for means correspond to Student's $t$-tests (ISS $=$ Injury severity score; AIS = abbreviated injury score; RTS = revised trauma score; TRISS = trauma injury severity score). 
Table 3. Types of aortic injury in crush trauma and non-crush trauma patients according to the classification proposed by Azizzadeh et al. ${ }^{8}$

\begin{tabular}{|c|c|c|c|c|c|}
\hline Type of aortic injury & & $\begin{array}{l}\text { All patients } \\
(n=74)\end{array}$ & $\begin{array}{l}\text { Crush trauma group } \\
(n=5)\end{array}$ & $\begin{array}{l}\text { Non-crush trauma group } \\
(n=69)\end{array}$ & $\begin{array}{l}P \\
\text { Value }\end{array}$ \\
\hline $\begin{array}{l}\text { Type } \\
\text { (aneurysm/pseudoaneurysm) }\end{array}$ & III & $3(4 \%)$ & 0 & $3(4.3 \%)$ & \\
\hline
\end{tabular}

Overall in-hospital mortality was $24.3 \%$ (18 patients). In hospital mortality was nil in the crush trauma group and $26.1 \%$ (18 patients) in the non-crush group $(p=0.32)$. Causes of death were: free aortic rupture in 7 cases; acute respiratory distress syndrome in 3; multisystem organ failure in 3; brain herniation in 2; septic shock in 2, and acute mesenteric ischaemia in 1 case. All aortic-related complications and aorticrelated mortality (8 patients in the overall population, 10.8\%) occurred in the non-crush group.

All crush trauma aortic injuries were medically managed. In the non-crush trauma 39 patients $(56.5 \%)$ received a conservative management, 22 patients $(31.9 \%)$ were operated on and 8 patients $(11.6 \%)$ underwent aortic endografting.

There were no differences in ICU and in-hospital stay between groups. The overall median ICU stay length was 15 days (range 0-123 days), whilst the median ICU stay length in the crush group was 18 days (range 4-51 days) and 15 days (range $0-123$ days) in the non-crush group $(p=0.89)$. The overall median in-hospital stay length was 30 days (range 0-228 days). The median in-hospital stay length was 28 days (range 13-77 days) in the crush group, and 30 days (range 0-228 days) in the non-crush group $(p=0.39)$.

After hospital discharge, clinical and imaging follow-up was available in all patients at a median time of 129 months (range 3-350 months). In the non-crush group, 3 patients had more than 5-year follow-up.

Overall survival estimated by the Kaplan-Meier method, including early mortality, was $78.4 \%$ at one year, $75.3 \%$ at five years, and $73 \% \%$ at ten years. Non-crush group survival was $76.8 \%$ at one year, $73.6 \%$ at five years, and $71.2 \% \%$ at ten years. In the crush group there was no mortality during follow-up (Fig. 3). Although there is a slight trend to a lower long-term survival in the non-crush group, no statistically significant differences between groups survival were detected $(p=0.21)$.

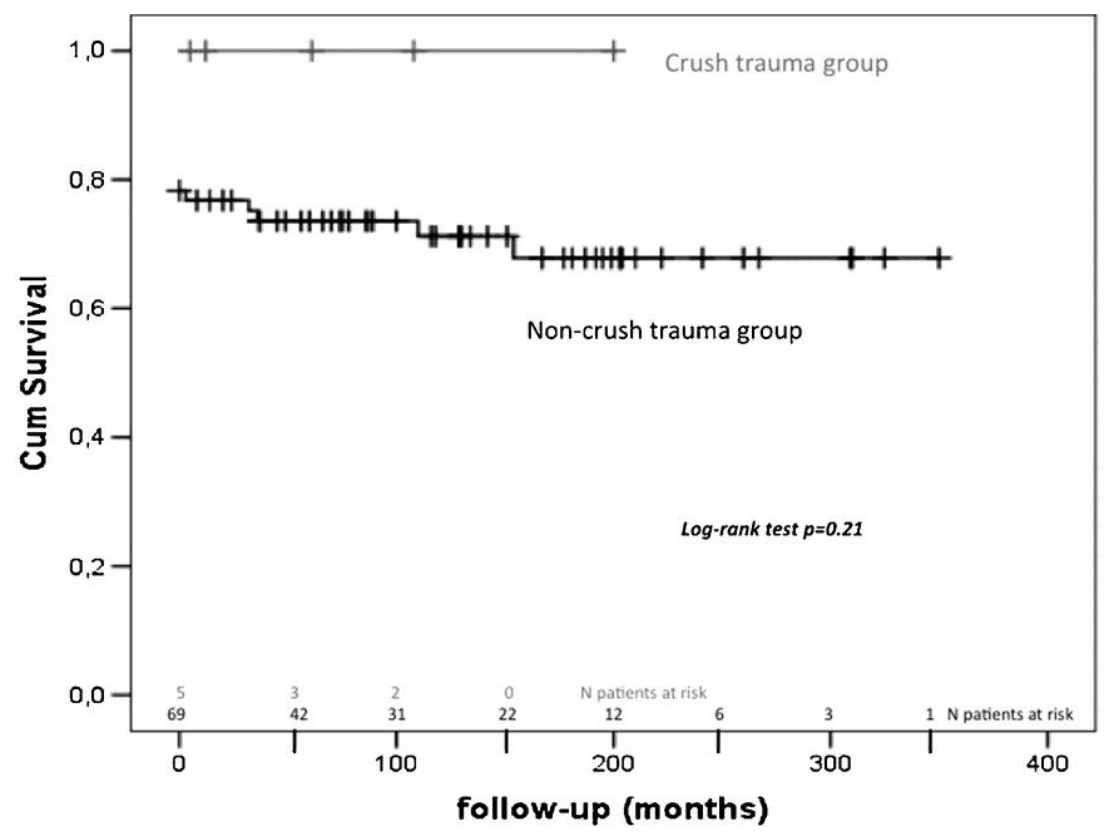

Fig. 3. Kaplan-Meier survival curves of crush thoracic trauma and non-crush thoracic trauma, including in-hospital mortality. 
No patient from the crush trauma group needed re-intervention because of aortic-related complication during the follow-up period. After hospital discharge, 11 patients from the surviving 51 patients in the non-crush group $(21.6 \%)$ developed an aortic-related complication, which required surgical or endovascular repair or caused the patient's death during the follow-up period $(21.6 \%$ non-crush group vs. $0 \%$ crush group, $p=0.57$ ). Cumulative survival free from aortic-related complications in the surviving patients of the non-crush group after hospital discharge ( $n=51$ patients) was $97.6 \%$ at 1 year, $91.9 \%$ at 5 years and $73.7 \%$ at 10 years ( Fig. 4).

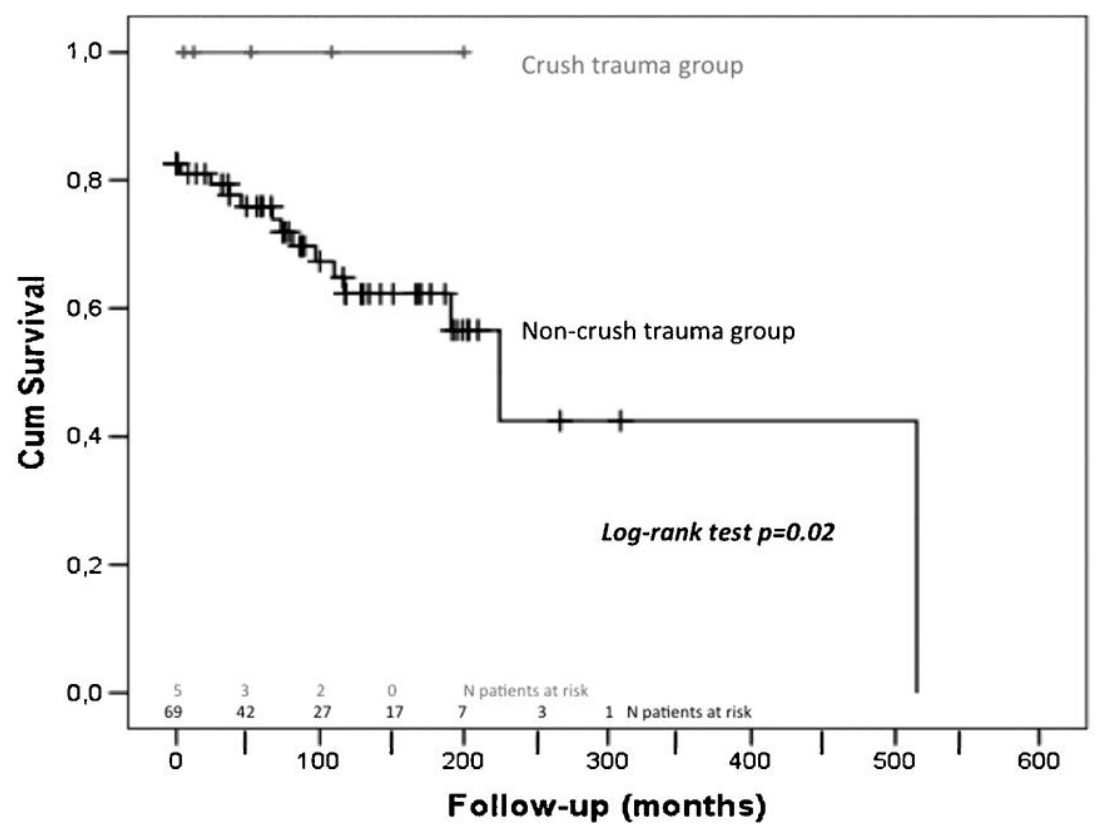

Fig. 4. Cumulative survival free from aortic-related complications in the surviving patients of the crush trauma and non-crush trauma groups after hospital discharge.

\section{Discussion}

Our results suggest that acute aortic injuries in crush trauma patients present a different mechanism, a lower severity and distinct location than ATAI in deceleration non-crush trauma. Our series also reflects a higher incidence of rhabdomiolysis and a higher probability of developing ARI in crush trauma patients.

A majority of ATAIs result from violent deceleration, most commonly as a result of a motor vehicle collision, especially head-on and side-impact collisions. Proposed mechanisms contributing to ATAI include shearing forces, rapid deceleration, hydrostatic forces, and the osseous pinch., 12 and 13 Rapid deceleration in the anteroposterior and lateral directions has been shown to be sufficient to result in cardiac displacement, producing torsion and shearing forces against the aorta at levels of relative immobility, mainly the ligamentum arteriosum, aortic root, and diaphragm. ${ }^{14}$ Nevertheless, deceleration mechanism of vascular injury after blunt thoracic trauma has never adequately explained other unusual sites. ${ }^{15}$ A combination of compression and upward thrust of the heart, which also involve shear and torsion, has been suggested. ${ }^{16}$ Lateral compression can result in severe internal chest deformation and shearing forces at the aortic isthmus. ${ }^{17}$ and 18

Increased intravascular pressure can exceed $2000 \mathrm{~mm} \mathrm{Hg}$ following direct compression of the aorta and has been termed the "water-hammer effect". ${ }^{19}$ The pressures created by this mechanism have been shown to result in mainly transverse tears at the level of the isthmus, ${ }^{20}$ but can also cause retrograde injury at the aortic root. ${ }^{13}$ Penetrating injury from rib and thoracic vertebral body fractures may also cause direct injury of the thoracic aorta. ${ }^{21}$ and 22 Another possible mechanism, the "osseous pinch", results from direct compression of the aorta between the anterior chest wall and the thoracic spine. ${ }^{3 \text { and } 12}$ An animal model study by Crass et al. ${ }^{3}$ showed that anteroposterior compression of the chest consistently results in transverse lacerations to the aortic isthmus when compressed between the anterior bony structure against the thoracic spine. However, the specific anterior bony structure causing vascular injury may vary. This mechanism may also explain concomitant injuries at branch vessels. ${ }^{3 \text { and } 12}$ 
Traumatic aortic injury is not a common injury, but aortic injury as the result of crush trauma is extremely uncommon (5 patients, $6.8 \%$ of all ATAIs in our study). Most published traumatic aortic injury series $^{23,24,25 \text { and } 26}$ do not report ATAI in crush trauma patients but mainly refer to deceleration trauma patients in either vehicle collisions or falls. Even in large series of crush trauma patients, the incidence of ATAI is remarkably low. In 215 acute thoracic crush trauma patients from Sichuan (China) earthquake evaluated by multidetector CT scan only 1 patient $(0.5 \%)$ presented a traumatic aortic injury. ${ }^{27}$ and 28

Our experience is consistent with the literature to date, yet provides some new insights about ATAI in crush trauma patients. In our series, aortic injuries in crush trauma patients have presented as low-risk injuries in all cases and differ from ATAI in non-crush trauma patients not only in the radiological severity (43.5\% of low-risk injuries) but also in its location, the mid and distal aorta and the aortic arch being more frequently affected.

Nowadays, identifying the low-risk patients with ATAI is of utmost importance because those patients will probably benefit from an initial medical management of the aortic injury. In our series, all crush trauma patients and the 21 surviving uncomplicated nonoperative patients of the non-crush group presented low-risk aortic injuries, namely types I and II of Azizzadeh's classification. ${ }^{8}$ Furthermore, ISS, RTS and TRISS scores punctuations at the time of admission at hospital were lower in this subgroup of uncomplicated nonoperative patients than in the subgroup of patients who suffering an aortic-related complication during follow-up. In a previous study, ${ }^{11}$ we found that the initial type of aortic lesion (HR: 2.94, $p=0.002$ ) and a TRISS score $>50 \%$ (HR: $1.49, p=0.042)$ on admission were risk factors for a worse long-term prognosis.

A tendency to a higher rhabdomiolysis, determined by a higher peak plasmatic CPK, and an increased risk of developing ARI in crush trauma patients has been found. In fact, one of the crush trauma patients developed ARF and required haemodiafiltration. Renal function may be also jeopardised by either open surgery or aortic endografting. Consequently, the higher incidence of low-risk aortic injuries and the increased presence of ARI in crush trauma patients would better sustain conservative approach to ATAI in crush trauma patients whenever a low-risk aortic injury is diagnosed.

\section{Limitations}

Although the number of crush trauma patients in other reported series of ATAI is small or inexistent, the number of patients in this series is small and the present study lacks sufficient statistical power to determine with confidence some clinical relevant differences.

This study also presents the limitations inherent to any retrospective series. The long time of retrospective analysis may influence the results generalisation. The criterion of ATAI management was not obviously consistent over the observation period of 30 years and was modified with the inclusion of technological advances.

\section{Conclusions}

Aortic injuries in crush thoracic trauma patients seem to present in a different clinical scenario, which may potentially need distinct considerations with regard to the aortic injuries in high-speed thoracic trauma. The increased risk of rhabdomiolysis, subsequent acute renal injury, and possible acute renal failure, as well as a tendency to develop lower-risk aortic wall injuries, must be considered when planning the initial management of aortic injuries in crush trauma. Nevertheless, we would like to emphasise the potential for rapid progression of traumatic aortic injuries, which makes mandatory serial radiological controls during the first three months after injury and diagnosis and then annually whenever a conservative management is selected.

\section{Conflict of interest}

The authors state that there are no potential conflicts of interest to be considered in this article. 


\section{References}

1. R.S. Smith, F.C. Chang. Traumatic rupture of the aorta: still a lethal injury. Am J Surg, 152 (December (6)) (1986), pp. 660-663.

2. P.G. Hanson. Pressure dynamics in thoracic aorta during linear deceleration. J Appl Physiol, 28 (January (1)) (1970), pp. 23-27.

3. J.R. Crass, A.M. Cohen, A.O. Motta, J.F. Tomashefski Jr., E.J. Wiesen. A proposed new mechanism of traumatic aortic rupture: the osseous pinch. Radiology, 176 (September (3)) (1990), pp. 645-649.

4. J.D. Schmoker, C.H. Lee, R.G. Taylor, A. Chung, L. Trombley, N. Hardin, et al. A novel model of blunt thoracic aortic injury: a mechanism confirmed?. J Trauma, 64 (April (4)) (2008), pp. 923-931.

5. S.P. Baker, B. O'Neill, W. Haddon Jr., W.B. Long. The injury severity score: a method for describing patients with multiple injuries and evaluating emergency care. J Trauma, 14 (March (3)) (1974), pp. 187-196.

6. H.R. Champion, W.J. Sacco, W.S. Copes, D.S. Gann, T.A. Gennarelli, M.E. Flanagan. A revision of the trauma score. J Trauma, May (29) (5) (1989), pp. 623-629.

7. H.R. Champion, W.J. Sacco, W.S. Copes. Injury severity scoring again. J Trauma, 38 (January (1)) (1995), pp. 9495.

8. A. Azizzadeh, K. Keyhani, C.C. Miller 3rd, S.M. Coogan, H.J. Safi, A.L. Estrera. Blunt traumatic aortic injury: initial experience with endovascular repair. J Vasc Surg, 49 (June (6)) (2009), pp. 1403-1408.

9. W.A. Lee, J.S. Matsumura, R.S. Mitchell, M.A. Farber, R.K. Greenberg, A. Azizzadeh, et al. Endovascular repair of traumatic thoracic aortic injury: clinical practice guidelines of the Society for Vascular Surgery. J Vasc Surg, 53 (January (1)) (2011), pp. 187-192.

10. R. Venkataraman, J.A. Kellum. Defining acute renal failure: the RIFLE criteria. J Intensive Care Med, 22 (JulyAugust (4)) (2007), pp. 187-193.

11. V.X. Mosquera, M. Marini, J.M. Lopez-Perez, J. Muniz-Garcia, J.M. Herrera, I. Cao, et al. Role of conservative management in traumatic aortic injury: comparison of long-term results of conservative, surgical, and endovascular treatment. J Thorac Cardiovasc Surg, 142 (September (3)) (2011), pp. 614-621.

12. A.M. Cohen, J.R. Crass, H.A. Thomas, R.G. Fisher, D.G.C.T. Jacobs. Evidence for the osseous pinch mechanism of traumatic aortic injury. AJR Am J Roentgenol, 159 (August (2)) (1992), pp. 271-274.

13. J.D. Creasy, C. Chiles, W.D. Routh, R.B. Dyer. Overview of traumatic injury of the thoracic aorta. Radiographics, 17 (January-February (1)) (1997), pp. 27-45.

14. H.M. Burkhart, G.A. Gomez, L.E. Jacobson, J.E. Pless, T.A. Broadie. Fatal blunt aortic injuries: a review of 242 autopsy cases. J Trauma, 50 (January (1)) (2001), pp. 113-115.

15. R.G. Fisher, Y. Ben-Menachem, F.P. Hadlock. Ascending aortic laceration. AJR Am J Roentgenol, 146 (February (2)) (1986), pp. 422-423

16. J.S. Williams, J.A. Graff, J.M. Uku, J.P. Steinig. Aortic injury in vehicular trauma. Ann Thorac Surg, 57 (March (3)) (1994), pp. 726-730.

17. D. Katyal, B.A. McLellan, F.D. Brenneman, B.R. Boulanger, P.W. Sharkey, J.P. Waddell. Lateral impact motor vehicle collisions: significant cause of blunt traumatic rupture of the thoracic aorta. J Trauma, 42 (May (5)) (1997), pp. 769-772.

18. P.C. Dischinger, B.M. Cushing, T.J. Kerns. Injury patterns associated with direction of impact: drivers admitted to trauma centers. J Trauma, 35 (September (3)) (1993), pp. 454-458 [discussion 8-9]. . 19. S.D. Steenburg, J.G. Ravenel, J.S. Ikonomidis, C. Schonholz, S. Reeves. Acute traumatic aortic injury: imaging evaluation and management. Radiology, 248 (September (3)) (2008), pp. 748-762.

20. J. Lundervall. The mechanism of traumatic rupture of the aorta. Acta Pathol Microbiol Scand, 62 (1964), pp. 3446.

21. J.V. Marco, J.S. Gregory. Posterior fracture of the left sixth rib causing late aortic laceration: case report. J Trauma, 42 (april (4)) (1997), pp. 736-737.

22. R. Murakami, H. Tajima, K. Ichikawa, Y. Kobayashi, K. Sugizaki, K. Yamamoto, et al.. Acute traumatic injury of the distal descending aorta associated with thoracic spine injury. Eur Radiol, 8 (1) (1998), pp. 60-62.

23. J. Cook, C. Salerno, B. Krishnadasan, S. Nicholls, M. Meissner, R. Karmy-Jones. The effect of changing presentation and management on the outcome of blunt rupture of the thoracic aorta. J Thorac Cardiovasc Surg, 131 (March (3)) (2006), pp. 594-600.

24. D. Demetriades, G.C. Velmahos, T.M. Scalea, G.J. Jurkovich, R. Karmy-Jones, P.G. Teixeira, et al. Diagnosis and treatment of blunt thoracic aortic injuries: changing perspectives. J Trauma, 64 (June (6)) (2008), pp. 14151418 [discussion 8-9].

25. D. Demetriades, G.C. Velmahos, T.M. Scalea, G.J. Jurkovich, R. Karmy-Jones, P.G. Teixeira, et al. Operative repair or endovascular stent graft in blunt traumatic thoracic aortic injuries: results of an American Association for the Surgery of Trauma Multicenter Study. J Trauma, 64 (March (3)) (2008), pp. 561-570 [discussion 70-1].

26. P.G. Teixeira, K. Inaba, G. Barmparas, C. Georgiou, C. Toms, T.T. Noguchi, et al. Blunt thoracic aortic injuries: an autopsy study. J Trauma, 70 (January (1)) (2011), pp. 197-202.

27. Z.H. Dong, Z.G. Yang, T.W. Chen, Y.C. Feng, Z.G. Chu, J.Q. Yu, et al. Crush thoracic trauma in the massive Sichuan earthquake: evaluation with multidetector CT of 215 cases. Radiology, 254 (January (1)) (2010), pp. 285-291.

28. Y. Hu, Y. Tang, Y. Yuan, T.P. Xie, Y.F. Zhao. Trauma evaluation of patients with chest injury in the 2008 earthquake of Wenchuan, Sechuan, China. World J Surg, 34 (April (4)) (2010), pp. 728-732. 